\title{
Catalytic benzylation of isomeric xylenes with benzyl alcohol in the presence of sulfuric acid
}

\author{
A. A. Rana*, M. Kamruzzaman and M. Saha \\ Department of Applied Chemistry and Chemical Engineering, University of Dhaka, Dhaka-1000, Bangladesh
}

\begin{abstract}
Benzylation of isomeric xylenes with benzyl alcohol in the presence of sulfuric acid as catalyst was studied and benzyl xylenes obtained in high yield. The effects of the variation of reaction parameters such as temperature, molar ratio of xylene to benzyl alcohol, amount of sulfuric acid and time of reactions were investigated. The yield of the products increased with the increase of each of the above-mentioned parameters.
\end{abstract}

Keywords: Benzylation; Benzyl alcohol; Isomeric xylenes.

\section{Introduction}

Benzylation of xylenes has earned much interest of the scientists since alkylated/benzylated hydrocarbons can be used as grease (Allison and Balack, 1953), transformer oil (Ashimov et. al., 1969), plasticizers (Vol-Epshtein et. al., 1964), pour point depressants (Lebedev et. al., 1960) and lubricating oil (Akhmedov et. al., 1987; Bataafsche de, 1952). Benzylation of aromatic compounds using homogeneous acid catalysts is a commercially practiced FriedelCraft type reaction in organic synthesis (Olah, 1963). Olah and co-workers are the pioneers of benzylation on aromatic hydrocarbons by using various solid or protic acid catalysts (Olah et. al., 1966). Aromatic hydrocarbons have been benzylated with benzyl alcohol and benzyl chloride in the presence of $\mathrm{ZnCl}_{2}$, niobic acid treated with phosphoric acid and $\mathrm{TiCl}_{4}, \mathrm{Fe}_{2} \mathrm{O}_{3}$ or $\mathrm{Fe}_{3} \mathrm{O}_{4}, \mathrm{HY}$ or $\mathrm{HL}$ zeolites and $\mathrm{TiCl}_{4}$ (Davister and Laszlo, 1993; Morais et. al., 1996). Catalytic alkylations of isomeric xylenes with different alcohols have been studied by several research groups (Bit et. al., 1986; Sabu et. al., 1994; Patra and Kumar, 2002). Reports are also available on the alkylation of isomeric xylenes with olefins and other alkylating agents in presence of different catalysts (Hiroshi and Higashimura, 1981; Rafique et. al., 2006; Satek et. al., 2004; Sharanappa et. al., 2004; Saha et. al., 1997; Kozorezov and Kuleshova, 1977). But alkylation of xylenes with aromatic alcohols especially benzyl alcohol was not studied so much. To the best of our knowledge, no attempt has so far been made to investigate the reaction of isomeric xylenes with benzyl alcohol in the presence of sulfuric acid.
Sulfuric acid is the most effective and inexpensive catalyst of the process, which has found wide industrial applications.

In the present work, the reactions of ortho-, para- and metaxylenes with benzyl alcohol in the presence of sulfuric acid as catalyst have been investigated and the yield of benzyl xylenes optimized using a set of input variables that included reactant parameters (molar ratio of xylene to benzyl alcohol, and amount of catalyst) and processing variables (temperature and reaction time).

\section{Materials and methods}

The reactions were carried out in a three necked round bottomed flask fitted with a condenser, a thermometer, a dropping funnel and a stirrer. Xylene-catalyst mixture was charged into the flask, heated to the temperature of the experiment, the benzyl alcohol was introduced into the mixture gradually over a certain period of time (time of addition) with constant stirring. The reaction mixture was stirred for another period of time (time of stirring) at the same temperature after the addition of the total amount of benzyl alcohol. The reaction mixture was then cooled to room temperature and neutralized with an equivalent amount of $10 \% \mathrm{KOH}$ solution. The neutralized reaction mixture was then dissolved in diethyl ether, washed with distilled water several times and dried with anhydrous magnesium sulfate. Unreacted reactants and solvent were distilled off at atmospheric pressure. The product thus obtained was subjected to fractionation by distillation and characterized by physicochemical and spectral means. 


\section{Results and discussion}

Benzylation of o-xylene

Reaction of $o$-xylene with benzyl alcohol was investigated in the presence of sulfuric acid over the temperature range of 80 to $130^{\circ} \mathrm{C}$. The reaction in all cases gave benzyl $o$-xylene. The effects of the variation of temperature, molar ratio of $o$ xylene to benzyl alcohol, concentration and amount of sulfuric acid and time of reaction on the yield of benzyl $o$-xylene have been shown in Table I.
In the IR spectrum, absorption bands at 697 and $722 \mathrm{~cm}^{-1}$ indicated the presence of 1,2,3-trisubstituted benzene ring, while bands at 831 and $879 \mathrm{~cm}^{-1}$ accounted for the presence of 1,2,4-trisubstituted benzene ring. Aromatic $\mathrm{C} \cdots \mathrm{C}$ stretch, saturated $\mathrm{C}-\mathrm{H}$ stretch and aromatic $=\mathrm{C}-\mathrm{H}$ were observed at 1602,2919 and $3060 \mathrm{~cm}^{-1}$ respectively.

The ${ }^{1} \mathrm{H}$ NMR-spectrum of benzyl $o$-xylene showed signals at $\delta=2.04-2.44$ ppm for six protons on the two- $\mathrm{CH}_{3}$ groups, while signals for two protons of $-\mathrm{CH}_{2}-$ on benzyl group

Table I. Benzylation of $o$-xylene with benzyl alcohol in the presence of $94 \%$ sulfuric acid.

\begin{tabular}{|c|c|c|c|c|c|c|}
\hline \multirow[t]{2}{*}{ Expt. No. } & \multicolumn{5}{|c|}{ Reaction Conditions } & \multirow{2}{*}{$\begin{array}{c}\text { \% Yield of } \\
\text { benzyl } \\
\text { o-xylene }\end{array}$} \\
\hline & Temp., ${ }^{\circ} \mathrm{C}$ & $\begin{array}{c}\text { Molar ratio of } \\
o \text {-xylene to } \\
\text { benzyl alcohol }\end{array}$ & $\begin{array}{c}\text { Amount of } \\
\text { catalyst, \% by } \\
\text { wt. of o-xylene }\end{array}$ & $\begin{array}{c}\text { Addition time } \\
\text { of benzyl } \\
\text { alcohol, h }\end{array}$ & $\begin{array}{l}\text { Stirring time } \\
\text { after addition } \\
\text { of reagent, } h\end{array}$ & \\
\hline 1 & 80 & $8: 1$ & 5 & 2 & 1 & 60.5 \\
\hline 2 & 100 & $8: 1$ & 5 & 2 & 1 & 72.5 \\
\hline 3 & 120 & $8: 1$ & 5 & 2 & 1 & 86.7 \\
\hline 4 & 130 & $8: 1$ & 5 & 2 & 1 & 94.8 \\
\hline 5 & 130 & $4: 1$ & 5 & 2 & 1 & 54.7 \\
\hline 6 & 130 & $5: 1$ & 5 & 2 & 1 & 63.6 \\
\hline 7 & 130 & $6: 1$ & 5 & 2 & 1 & 75.8 \\
\hline 8 & 130 & $8: 1$ & 1 & 2 & 1 & 63.9 \\
\hline 9 & 130 & $8: 1$ & 2 & 2 & 1 & 79.4 \\
\hline 10 & 130 & $8: 1$ & 3 & 2 & 1 & 89.1 \\
\hline 11 & 130 & $8: 1$ & 5 & 2 & 2 & 95.9 \\
\hline
\end{tabular}

From Table I, it is clear that the yield of the product increased with the increase of temperature (Expt. No. 1, 2, 3 $\& 4)$ and molar ratio of $o$-xylene to benzyl alcohol (Expt. No. 4, 5, $6 \& 7$ ). The yield of the product also depended on the amount of catalyst and reaction time. The yield of benzyl $o$-xylene increased with the increase of amount of catalyst (Expt. No. 4, 8, 9 \& 10) and reaction time (Expt. No. 4 \& 11).

Therefore, the following conditions may be considered as optimum (yield $=95.9 \%$ ) for the production of benzyl $o$ xylene: temperature $=130^{\circ} \mathrm{C}$, molar ratio of $o$-xylene to benzyl alcohol $=8: 1$, amount of $94 \%$ sulfuric acid $=5 \%$ by wt. of $o$-xylene and total reaction time (time of addition and time of stirring after the addition of reagent) $=4 \mathrm{~h}$.

The UV spectrum of benzyl $o$-xylene showed a strong absorption band at $\lambda_{\max }=276.80 \mathrm{~nm}$ in $0.01 \mathrm{M}$ methanol solution. were observed at $\delta=3.81-4.04 \mathrm{ppm}$. Signals for all the protons on two aromatic rings were observed at $\delta=6.80-7.36$ ppm.

Benzyl $o$-xylene had b.p. $270^{\circ} \mathrm{C} ; d_{4}{ }^{20} 0.9252$ and $n_{D}{ }^{20} 1.5203$ (Saha et. al., 2001).

\section{Benzylation of p-xylene}

The results of the reaction of $p$-xylene with benzyl alcohol in the presence of sulfuric acid are presented in the Table II.

The reaction gave 2-benzyl-1,4-dimethylbenzene. The effects of the variation of temperature, molar ratio of $p$ xylene to benzyl alcohol, amount of sulfuric acid, and time of reaction on the yield of the product were investigated. The yield of 2-benzyl-1,4-dimethylbenzene increased with the increase of temperature (Expt. No. 1, 2, 3 \& 4), molar ratio of $p$-xylene to benzyl alcohol (Expt. No. 4, 5, $6 \&$ 7), amount of catalyst (Expt. No. 7, 8, 9, 10 \&11) and time of reaction (Expt. No. 7 \&12). 
Table II. Benzylation of $p$-xylene with benzyl alcohol in the presence of $94 \%$ sulfuric acid

\begin{tabular}{|c|c|c|c|c|c|c|}
\hline \multirow[t]{2}{*}{ Expt. No. } & \multicolumn{5}{|c|}{ Reaction Conditions } & \multirow{2}{*}{$\begin{array}{l}\% \text { 2-ben } \\
\text { zyl-1,4- } \\
\text { dimethyl } \\
\text { benzene }\end{array}$} \\
\hline & Temp., ${ }^{\circ} \mathrm{C}$ & $\begin{array}{l}\text { Molar ratio of } \\
p \text {-xylene to } \\
\text { benzyl alcohol }\end{array}$ & $\begin{array}{c}\text { Amount of } \\
\text { catalyst, } \% \text { by } \\
\text { wt. of } p \text {-xylene }\end{array}$ & $\begin{array}{c}\text { Addition time } \\
\text { of benzyl } \\
\text { alcohol, h }\end{array}$ & $\begin{array}{l}\text { Stirring time } \\
\text { after addition } \\
\text { of reagent, } h\end{array}$ & \\
\hline 1 & 80 & $4: 1$ & 5 & 2 & 1 & 47.1 \\
\hline 2 & 100 & $4: 1$ & 5 & 2 & 1 & 52.1 \\
\hline 3 & 120 & $4: 1$ & 5 & 2 & 1 & 56.8 \\
\hline 4 & 130 & $4: 1$ & 5 & 2 & 1 & 62.9 \\
\hline 5 & 130 & $6: 1$ & 5 & 2 & 1 & 71.6 \\
\hline 6 & 130 & $8: 1$ & 5 & 2 & 1 & 84.1 \\
\hline 7 & 130 & $10: 1$ & 5 & 2 & 1 & 89.2 \\
\hline 8 & 130 & $10: 1$ & 1 & 2 & 1 & 58.2 \\
\hline 9 & 130 & 10:1 & 2 & 2 & 1 & 66.5 \\
\hline 10 & 130 & $10: 1$ & 3 & 2 & 1 & 74.9 \\
\hline 11 & 130 & $10: 1$ & 4 & 2 & 1 & 85.1 \\
\hline 12 & 130 & $10: 1$ & 5 & 2 & 2 & 92.6 \\
\hline
\end{tabular}

Therefore, the maximum yield $(92.6 \%)$ of 2-benzyl-1,4dimethylbenzene was obtained under the following conditions: temperature $=130^{\circ} \mathrm{C}$, molar ratio of $p$-xylene to benzyl alcohol $=10: 1$, amount of $94 \%$ sulfuric acid $=5 \%$ by wt. of $p$-xylene and total reaction time (time of addition and time of stirring after the addition of reagent $)=4 \mathrm{~h}$.

The UV spectrum of 2-benzyl-1,4-dimethylbenzene showed a strong absorption band at $\lambda_{\max }=277.80 \mathrm{~nm}$ in $0.01 \mathrm{M}$ methanol solution.

The IR spectrum of 2-benzyl-1,4-dimethylbenzene showed absorption bands at 809 and $880 \mathrm{~cm}^{-1}$ for the presence of 1,2,4-trisubstituted aromatic ring and band at $2923 \mathrm{~cm}^{-1}$ accounted for saturated $\mathrm{C}-\mathrm{H}$ stretching. The spectrum also showed absorption bands at 3025 and $1603 \mathrm{~cm}^{-1}$ for aromatic $=\mathrm{C}-\mathrm{H}$ stretching and aromatic ring $\mathrm{C} \cdots \mathrm{C}$ stretching, respectively.

The ${ }^{1} \mathrm{H}$ NMR-spectrum of 2-benzyl-1,4-dimethylbenzene showed signals at $\delta=2.11-2.34 \mathrm{ppm}$ for all six protons on the two $-\mathrm{CH}_{3}$ groups, while signals for two protons of $-\mathrm{CH}_{2}-$ on benzyl group were observed at $\delta=3.83-4.07 \mathrm{ppm}$. Signals for all the protons on two aromatic rings were observed at $\delta=6.7-7.36 \mathrm{ppm}$.

Table III. Benzylation of $p$-xylene with benzyl alcohol in the presence of $94 \%$ sulfuric acid

\begin{tabular}{|c|c|c|c|c|c|c|}
\hline \multirow[t]{2}{*}{ Expt. No. } & \multicolumn{5}{|c|}{ Reaction Conditions } & \multirow{2}{*}{$\begin{array}{c}\% \text { Yield of } \\
\text { benzyl } \\
m \text {-xylene }\end{array}$} \\
\hline & Temp., ${ }^{\circ} \mathrm{C}$ & $\begin{array}{l}\text { Molar ratio of } \\
m \text {-xylene to } \\
\text { benzyl alcohol }\end{array}$ & $\begin{array}{c}\text { Amount of } \\
\text { catalyst, \% by } \\
\text { wt. of m-xylene }\end{array}$ & $\begin{array}{c}\text { Addition time } \\
\text { of benzyl } \\
\text { alcohol, h }\end{array}$ & $\begin{array}{l}\text { Stirring time } \\
\text { after addition } \\
\text { of reagent, h }\end{array}$ & \\
\hline$\overline{1}$ & 100 & $4: 1$ & 5 & 2 & 1 & 61.3 \\
\hline 2 & 110 & $4: 1$ & 5 & 2 & 1 & 64.8 \\
\hline 3 & 120 & $4: 1$ & 5 & 2 & 1 & 65.3 \\
\hline 4 & 130 & $4: 1$ & 5 & 2 & 1 & 69.4 \\
\hline 5 & 130 & $6: 1$ & 5 & 2 & 1 & 77.4 \\
\hline 6 & 130 & $8: 1$ & 5 & 2 & 1 & 85.6 \\
\hline 7 & 130 & $10: 1$ & 5 & 2 & 1 & 92.8 \\
\hline 8 & 130 & $4: 1$ & 1 & 2 & 1 & 59.3 \\
\hline 9 & 130 & $4: 1$ & 2 & 2 & 1 & 63.8 \\
\hline 10 & 130 & $4: 1$ & 3 & 2 & 1 & 66.2 \\
\hline 11 & 130 & $10: 1$ & 5 & 2 & 2 & 94.1 \\
\hline
\end{tabular}


2-Benzyl-1,4-dimethylbenzene had b.p. $290^{\circ} \mathrm{C} ; d_{4}{ }^{20} 1.0055$ and $n_{D}{ }^{20} 1.5737$ (Saha et al., 2001).

Benzylation of m-xylene

The influence of the variation of reaction parameters on the reaction of $m$-xylene with benzyl alcohol in presence of $94 \%$ sulfuric acid has been shown in Table III. The reaction of $m$ xylene with benzyl alcohol under the conditions studied gave benzyl $m$-xylene.

As can be seen from Table III, the yield of benzyl $m$-xylene increased with the increase of temperature (Expt. No. 1, 2, 3 and 4), molar ratio of $m$-xylene to benzyl alcohol (Expt. No. 4, 5, 6, and 7), amount of catalyst (Expt. No. 1, 8, 9, and 10) and reaction time (Expt. No. 7, 11).

Thus, the reaction conditions so far studied, the best yield $94.1 \%$ of benzyl $m$-xylene was obtained under the following conditions: temperature $=130^{\circ} \mathrm{C}$, molar ratio of $m$-xylene to benzyl alcohol $=10: 1$, amount of sulfuric acid $=5 \%$ by wt. of $m$-xylene and total reaction time (time of addition and time of stirring after the addition of reagent) $=4 \mathrm{~h}$.

The UV spectrum of benzyl $m$-xylene in $0.01 \mathrm{M}$ methanol solution showed a strong absorption band at $\lambda_{\max }=276.40$ nm.

The 1R spectrum of benzyl $m$-xylene showed the absorption bands at 697 and $769 \mathrm{~cm}^{-1}$ for 1,2,3-trisubstituted benzene ring while bands at 832 and $878 \mathrm{~cm}^{-1}$ showed the presence of 1,2,4-trisubstituted benzene ring. Other strong absorption bands at 3025, 2922 and $1603 \mathrm{~cm}^{-1}$ indicated the presence of aromatic $=\mathrm{C}-\mathrm{H}$ stretching, saturated $\mathrm{C}-\mathrm{H}$ stretching and aromatic ring $\mathrm{C} \cdots \mathrm{C}$ stretching in the aromatic ring respectively.

The ${ }^{1} \mathrm{H}$ NMR-spectrum of benzyl $m$-xylene showed signals at $\delta=6.7-7.36 \mathrm{ppm}$ for all aromatic ring protons. Signals for six protons on the methyl groups and two protons of $-\mathrm{CH}_{2}$ on benzyl group were observed at $\delta=2.08-2.34 \mathrm{ppm}$ and $\delta$ $=3.81-4.05$ ppm respectively.

Benzyl $m$-xylene had b.p. $290^{\circ} \mathrm{C} ; d_{4}{ }^{20} 1.0035$ and $n_{\mathrm{D}}{ }^{20}$ 1.5621 (Saha et al., 2001).

\section{Conclusion}

The yield of benzylation of isomeric xylenes with benzyl alcohol in the presence of sulfuric acid as catalyst was optimized and the benzylated products were characterized. Results of this study indicated that the effects of temperature, molar ratio of isomeric xylenes to benzyl alcohol, amount of catalyst, and time of reaction were significant. The yield of the products increased with the increase of each of the above-mentioned parameters.

\section{References}

Akhmedov AI, Lerslina AN and Isakov EU (1987), Manufacture of synthetic hydrocarbon oil in batch units. Khim. Tekhnol. Topl. Masel. 10: 26-27.

Allison, JR and Balack NML (1953), Lubricating grease. U.S. Patent 2(628): 195-202.

Ashimov MA, Mursalova MA and Kanzaveli SE (1969), Alkylation of benzene by a wide fraction of olefins $\left(30-250^{\circ} \mathrm{C}\right)$, products of the cracking of n-olefins of transformer oil. Dolk. Akad. Nauk. Azerb. 25(7): 203.

Bataafsche de NN (1952), Alkylated aromatic hydrocarbons suitable as a lubricating oil. Dutch 70: 426.

Bit KC, Goswami TK and Bhattacharya RN (1986), Alkylation of xylenes to polyalkylbenzenes. Fuel Sci. Tech. 5(3): 137-45.

Davister M and Laszlo P (1993), Explanation of a paradoxical selectivity in friedel-crafts alkylation under heterogeneous catalysis. Tetrahedron Lett. 34: 533-536.

Hiroshi H and Higashimura T (1981), Alkylation of aromatic hydrocarbons with divinylbenzene by solid polymeric oxo acids. Poly. J. 13(9): 915-17.

Kozorezov Yu. I and Kuleshova AN (1977), Study of the kinetics of the liquid-phase alkylation of aromatic hydrocarbons by olefins on aluminum oxide promoted by boron fluoride. V. Alkylation of $m$ - xylene by propylene. Kinetika i Kataliz 18(3): 813-14.

Lebedev NN, Nicolseu IV, Mircha I and Nikshin GI (1960), Title. Izvest, Akad. Naku. USSR, Otdel. Khim. 94.

Morais M, Torres EF, Carmo LMPM, Pastura NMR, Gonzalez WA, dos Santos ACB and Lachter ER (1996), Benzylation of toluene and anisole by benzyl alcohol catalyzed by niobic acid. Catal. Today 28(1-2): 17-21.

Olah GA (1963), Friedel-Crafts and Related Reactions, Vol1, Wiley, New York. 
Olah GA, Kuhn SJ and Flood SH (1966), Aromatic substitution. $\mathrm{X}$. The $\mathrm{AlCl}_{3} \cdot \mathrm{CH}_{3} \mathrm{NO}_{2}$-catalyzed benzylation of benzene and $n$-alkylbenzenes with benzyl chloride in nitromethane solution. J. Am. Chem. Soc. 84: 16881695.

Patra, CR and Kumar R (2002), Isopropylation of xylenes catalyzed by Ultrastable Zeolite Y (USY) and some other solid acid catalysts. J. Catal. 212: 216-224.

Rafique RF, Sarker MAB, Alam MA and Saha M (2006), Cyclohexylation of isomeric xylenes with cyclohexyl chloride in the presence of anhydrous aluminum chloride. Dhaka Univ. J. Sci. 54(2): 133-135.

Sabu KR, Rao KVC and Nair CGR (1994), Alkylation of benzene, toluene and xylene isomers with $\mathrm{C}_{2}, \mathrm{C}_{3}$ and $\mathrm{C}_{4}$ aliphatic alcohols on $\mathrm{TiO}_{2}-\mathrm{SiO}_{2}-\mathrm{Al}_{2} \mathrm{O}_{3}$ and $\mathrm{MoO}_{3}$ $\mathrm{SiO}_{2}-\mathrm{Al}_{2} \mathrm{O}_{3}$. Indian. J. Chem. Sect. B: Org. Chem. 33B(11): 1053-1061.

Saha M, Alam A, Kamruzzaman K, Mazumder M and Hasan M (2001), Benzylation of xylenes with benzyl alcohol in the presence of benzenesulphonic acid. Bangladesh J. Sci. Ind. Res. 36(1-4): 97-100.
Saha M, Chowdhury S, Jolly YN, Sarker MA B and Saha D (1997), A study of alkylation of xylenes with decene1 in the presence of $p$-toluenesulphonic acid. Bangladesh J. Sci. Ind. Res. 32(2): 259-262.

Satek LC, Jevne SC and Chhatwal SS (2004), Regioselective preparation of 5-tert-butyl- $m$-xylene from $m$-xylene and isobutylene using a solid, active clay catalyst. U.S. Pat. Appl. Publ. 9

Sharanappa N, Pai S and Bokade VV (2004), Selective alkylation and disproportionation of ethylbenzene in the presence of other aromatics. J. Mol. Catal. A: Chem. 217(1-2): 185-191.

Vol-Epshtein AB, Krichko AA an d Filippychev GF (1964). Utilization of the alkylbenzene fraction obtained in the reduction of cumene as solvents. Neftepererabotka Neftekhim. Nauchn, Tekhn. Sb. 6: 33-36.

Received: 12 october 2011; Revised: 30 December 2012; Accepted: 01 January 2013. 